\title{
Hepatocellular Carcinoma is an Emerging Issue Now in Iran
} Seyed Moayed Alavian ${ }^{1, *}$

${ }^{1}$ Baqiyatallah Research Center for Gastroenterology and Liver Diseases, Baqiyatallah University of Medical Sciences, Tehran, Iran

"Corresponding author: Seyed Moayed Alavian, Baqiyatallah Research Center for Gastroenterology and Liver Diseases, Baqiyatallah University of Medical Sciences, Tehran, Iran. Tel/fax: +98-2188945186-8, E-mail: alavian@thc.ir

Received 2017 December 20; Accepted 2017 December 24.

Keywords: Hepatitis B, Hepatitis C, Hepatocellular Carcinoma

\section{Introduction}

Burden of hepatocellular carcinoma (HCC) is an increasing issue in the world. HCC is the most common primary cancer in the liver and it is the third cause of death related to cancer worldwide (1). A rise in the prevalence of HCC has continued due to presence of a large pool of patients infected with hepatitis $\mathrm{C}$ virus (HCV) and hepatitis $\mathrm{B}$ virus (HBV) infections.

Today, a wide variety of imaging modalities including ultrasonography, computed tomography (CT), magnetic resonance imaging (MRI), isotope scan, and positron emission tomography (PET) are currently used in the evaluation of patients with HCC. These imaging techniques have a definitive role in the early diagnosis and better staging of the disease (1). Early diagnosis has led to first-stage treatment using radiological interventions and has also increased the survival of the patients significantly (2-4). Moreover, the use of one method of imaging such as ultrasonography and periodic measurements of serum alpha-fetoprotein are strongly suggested as the main tools in the early diagnosis of HCC in high risk groups (5). There are various nonsurgical therapeutic options in HCC patients, including traditional transarterial chemoembolization (TACE), transarterial embolization, percutaneous ethanol injection, radiofrequency ablation (RFA), and chemotherapy (6).

\section{Hepatitis B and HCC}

HBV infection is the most cause of HCC in the world and Iran (7). It is more prevalent in regions with high endemicity for HBV infection such as Asia $(8,9)$. Burden of HBV infection has decreased due to HBV vaccination in most parts of the world (10-12), but the higher age of HBV-infected patients with longer duration and low rate of anti-viral therapy still put them at a higher risk for HCC. It is the most preventable cancer with $\mathrm{HBV}$ vaccination $(8,13)$, however the impact of HBV vaccination on the incidence of HCC will be more evident in the future. Shiraz liver transplantation center reported that the most common cause of cirrhosis was HBV related, and the majority of patients with HCC in their center were also HBV related $(14,15)$.

\section{Hepatitis C and HCC}

HCV, as a global health hazard, has infected around 71 million peoples in the world (16). Chronic HCV infection can lead to long-term sequels such as cirrhosis, hepatocellular carcinoma, and death (17). After control of HBV infection, an increase in the incidence of HCC, most likely reflecting the increased prevalence of HCV infection, liver cirrhosis due to obesity, and diabetes mellitus, has been reported in some countries in the world $(9,18,19)$. Infection with HCV is responsible for an increase in the number of cases of HCC among US veterans (20).

After establishment of cirrhosis, HCC develops in patients with a rate of 1 to 4 percent per year and after 20 years we will have significant cases with HCC in this group. There is a dilemma about the relationship between directly acting antivirals (DAAs) for the treatment of HCV and the risk of HCC (21). It seems that in cirrhotic patients, we should be aware of occult HCC and exacerbation after elimination of HCV infection. Patients with previous HCC should be carefully followed to confirm complete HCC remission before starting antiviral therapy, and intense follow-up should be performed after DAA treatment (21).

\section{Obesity, Diabetes and HCC}

The insulin resistance syndrome, obesity and diabetes are emerging issues in the industrial community and they play a risk factor for HCC in the world nowadays (22). 
Lifestyle factors such as obesity, low activity, diabetes and alcohol consumption can contribute to occurrence of HCC. Obesity and diabetes increase the risk of HCC by increasing the risk of nonalcoholic fatty liver disease (NAFLD) and cirrhosis. Insulin resistance results in an inflammatory cascade, which leads to the development of nonalcoholic steatohepatitis (NASH), and finally mediates carcinogens to develop HCC. The incidence of NASH is expected to increase due to the growing epidemic of diabetes and obesity in the world (22).

\section{In Conclusion}

We should be more careful regarding early diagnosis of HCC with new radiological modalities and blood testing. In HBV and HCV patients more interventions must be integrated on the management of prevention of cirrhosis. In Iran, absence of a guideline for screening and management of HCC is one of our conflicts. We are sure that with attention to consensus guidelines and using new radiological modalities in diagnosis and therapy, the patient's survival will increase in the future in Iran.

\section{References}

1. Ghanaati H, Alavian SM, Jafarian A, Ebrahimi Daryani N, Nassiri-Toosi $\mathrm{M}$, Jalali $\mathrm{AH}$, et al. Imaging and Imaging-Guided Interventions in the Diagnosis and Management of Hepatocellular Carcinoma (HCC)Review of Evidence. Iran J Radiol. 2012;9(4):167-77. doi: 10.5812/iranjradiol.8242. [PubMed: 23407596].

2. Xu Y, Xiao A, Yang J, Zhang Z, Zhang G. Assessment of lipiodol deposition and residual cancer for hepatocellular carcinoma after transcatheter arterial chemoembolization via iodine based material decomposition images with spectral computed tomography imaging, a preliminary Study. Iran J Radiol. 2015;12(4):26009. doi: 10.5812/iranjradiol.26009. [PubMed: 26715981].

3. Jalli R, Jafari SH, Sefidbakht S, Kazemi K. Comparison of the accuracy of DWI and ultrasonography in screening hepatocellular carcinoma in patients with chronic liver disease. Iran J Radiol. 2015;12(1):12708. doi:10.5812/iranjradiol.12708. [PubMed: 25785178].

4. Hemmati H, Karimian M, Moradi H, Farid Marandi K, Haghdoost A. Endovascular treatment of a huge hepatic artery aneurysm by coil embolization method, a case report. Iran J Radiol. 2015;12(3):5200. doi: 10.5812/iranjradiol.5200. [PubMed: 26528386].

5. Kim CY, Kim BR, Lee SS, Jeon DH, Lee CM, Kim WS, et al. Clinical features of hepatitis $\mathrm{B}$ and $\mathrm{C}$ virus infections, with high alpha fetoprotein levels but not hepatocellular carcinoma. Medicine (Baltimore). 2017;96(2):5844. doi: 10.1097/MD.0000000000005844. [PubMed: 28079817].

6. Yang B, You X, Yuan ML, Qin TQ, Duan LJ, He J, et al. Transarterial ethanol ablation combined with transarterial chemoembolization for hepatocellular carcinoma with portal vein tumor thrombus. Hepat Mon. 2016;16(8):37584. doi: 10.5812/hepatmon.37584. [PubMed: 27799963].
7. Alavian SM, Haghbin H. Relative importance of hepatitis B and C viruses in hepatocellular carcinoma in EMRO countries and the middle east, a systematic review. Hepat Mon. 2016;16(3):35106. doi: 10.5812/hepatmon.35106. [PubMed: 27226803].

8. Rezaee R, Aghcheli B, Poortahmasebi V, Qorbani M, Alavian SM, Jazayeri SM. Prevalence of national responsiveness to HBV vaccine after 22 years of Iranian expanded program on immunization (EPI), a systematic review and meta analysis study. Hepat Mon. 2015;15(5):23618. doi: 10.5812/hepatmon.15(04)2015.23618. [PubMed: 26045701].

9. Blum HE. Hepatocellular carcinoma: HCC. Hepat Mon. 2011;11(2):6970. [PubMed: 22087121].

10. Hajarizadeh B, Mesgarpour B, Nasiri MJ, Alavian SM, Merat S, Poustchi $\mathrm{H}$, et al. Estimating the prevalence of hepatitis B virus infection and exposure among general population in Iran. Hepat Mon. 2017;17(8) doi: 10.5812/hepatmon.11715.

11. Stawinska Witoszynska B, Zysnarska M, Krzywinska Wiewiorowska M, Wojtyla Buciorab P, Krzyzaniak A, Wieckowska B. Trends in the incidence rates of chronic hepatitis B in poland in the years 2005-2013. Hepat Mon. 2016;16(8):32692. doi: 10.5812/hepatmon.32692. [PubMed: 27799960].

12. Sosa Jurado F, Hilda Rosas Murrieta N, Guzman Flores B, Perez Zempoaltecalt C, Patricia Sanchez Torres A, Ramirez Rosete L, et al. Prevalence of serologic hepatitis B markers in blood donors from puebla, Mexico, the association of relatively high levels of anti-core antibodies with the detection of surface antigen and genomic DNA. Hepat Mon. 2016;16(6):36942. doi: 10.5812/hepatmon.36942. [PubMed: 27630726].

13. La Fauci V, Riso R, Facciola A, Ceccio C, Lo Giudice D, Calimeri S, et al. Response to anti-HBV vaccine and 10-year follow-up of antibody levels in healthcare workers. Public Health. 2016;139:198-202. doi: 10.1016/j.puhe.2016.08.007. [PubMed: 27600791].

14. Geramizadeh B, Nikeghbalian S, Kazemi K, Shamsaifar A, Bahador A, Salahi $\mathrm{H}$, et al. Hepatocellular carcinoma in explanted livers of patients with genotype $\mathrm{d}$ HBV cirrhosis: report of the first experience from Iran. Arch Iran Med. 2013;16(6):348-50. [PubMed: 23725068].

15. Geramizadeh B, Nikeghbalian S, Shamsaifar A, Kazemi K, Malekhosseini SA. Hepatocellular carcinoma in two patients with autoimmune hepatitis, a single center experience and review of the literature. Hepat Mon. 2013;13(4):7957. doi: 10.5812/hepatmon.7957. [PubMed: 23805159].

16. Gower E, Estes C, Blach S, Razavi-Shearer K, Razavi H. Global epidemiology and genotype distribution of the hepatitis C virus infection.J Hepatol. 2014;61(1 Suppl):45-57. doi: 10.1016/j.jhep.2014.07.027. [PubMed: 25086286].

17. Hajarizadeh B, Grebely J, Dore GJ. Epidemiology and natural history of HCV infection. Nat Rev Gastroenterol Hepatol. 2013;10(9):553-62. doi: 10.1038/nrgastro.2013.107. [PubMed: 23817321].

18. El Serag HB, Mason AC. Rising incidence of hepatocellular carcinoma in the United States. N Engl J Med. 1999;340(10):745-50. doi: 10.1056/NEJM199903113401001. [PubMed: 10072408].

19. El Serag HB. Hepatocellular carcinoma and hepatitis $C$ in the United States. Hepatology. 2002;36(5 Suppl 1):74-83. doi: 10.1053/jhep.2002.36807. [PubMed: 12407579].

20. El Serag HB, Mason AC. Risk factors for the rising rates of primary liver cancer in the United States. Arch Intern Med. 2000;160(21):322730. [PubMed: 11088082].

21. Strazzulla A, Iemmolo RMR, Carbone E, Postorino MC, Mazzitelli M, De Santis M, et al. The risk of hepatocellular carcinoma after directly acting antivirals for hepatitis c virus treatment in liver transplanted patients, Is it real?. Hepat Mon. 2016;16(11):41933. doi: 10.5812/hepatmon.41933. [PubMed: 28070200].

22. Montella M, Crispo A, Giudice A. HCC, diet and metabolic factors: Diet and HCC. Hepat Mon. 2011;11(3):159-62. [PubMed: 22087137]. 